\title{
O Transporte Público em Cuiabá-MT e a Segurança do Trabalhador
}

\section{Public transport in Cuiabá and Worker Safety}

\author{
1'Margarida Marchetto (marchetto.ro@gmail.com), ${ }^{2}$ Sergio Luiz Moraes Magalhães, ${ }^{3}$ Edson N. Brasil de \\ Oliveira, ${ }^{4}$ Antônio Severo Junior \\ 12 Professores dos Programas de Pós-Graduação em Recursos em Hídricos, Engenharia de Edificações e \\ Ambiental e Segurança do Trabalho da Faculdade de Arquitetura-FAET, Engenharia e Tecnologia da \\ Universidade Federal de Mato Grosso-UFMT \\ ${ }^{3}$ Graduando do curso de Engenharia Civil da FAET-UFMT \\ ${ }^{4}$ Técnico em segurança do Trabalho
}

Recebido: Jul 2015 Aceito:Ago/2015

\begin{abstract}
Resumo: O relevante crescimento do meio urbano nas últimas décadas gerou dificuldades para as cidades em diversas áreas como o transporte, o trânsito, meio ambiente, entre outras. O Sistema de transporte coletivo é fundamental para diminuir as distancias entre regiões, pois interfere diretamente na economia, educação entre outros fatores básicos para o cidadão. Segurança, agilidade, custos e confiabilidade são essenciais para um sistema de transporte coletivo, pois a evolução continua das cidades, leva em conta tais fatores, tornando-se questões estratégicas que não podem ser desconsideradas dadas as possíveis consequências. Nesse trabalho será avaliada a situação do transporte público em Cuiabá após a paralisação das obras de infra-estrutura viárias, especialmente o VLT, além das normas que regulamentam o Transporte, sendo estas apreciadas pelo Conselho Municipal de Transporte - CMT. Sabendo que o grau de risco de Empresas de Transportes que atuam na área de transporte de pessoas, "coletivo" é o de $\mathrm{n}^{\mathbf{o}} 3$. As mesmas precisam obrigatoriamente contar com técnicos em segurança do trabalho correspondendo as exigências estabelecidas por lei. Para atender a legislação, as atividades da empresa exigem treinamentos, realização de ginástica laboral com os funcionários, vistoria nos postos de trabalho, levantamento de problemas diversos relacionados como a sinalização de segurança, prazos de validade dos extintores, situação da iluminação, treinamento de funcionários entre diversas outras.
\end{abstract}

Palavras-Chave: Meios de transportes; Segurança do Trabalho; Normas.

\begin{abstract}
The significant growth of the urban areas in the last few decades, has created difficulties for the cities in different areas such as transport, the transit system, the environment, among others. The collective transport System is essential to reduce the distances between regions, because directly interferes in the economy, education and other basic factors for the citizen. Security, agility, cost and reliability are essential to the system of public transport, considering the constant development of the cities, takes into account such factors, becoming strategic issues that cannot be ignored given the possible consequences. In this article, we evaluate the Public Transport situation after the standstill of the road infrastructure project, specially the VLT, beyond rules that regulates the same. Laws regulating the issues related to transport are assessed by the Municipal Council of Transport - CMT. Knowing that the risk level of Transport Companies, which are responsible in transporting people, is level 3, those laws must necessarily rely on technical security in the work corresponding to the requirements laid down by law. To meet the legislation, the company's activities require training, workout at work, overhaul at the workstation, listing the problems concerning safety signs, deadline of extinguishers, state of illumination, training employees among others.
\end{abstract}

Keywords: Public Transport; Workplace Safety; Standards.

\section{INTRODUÇÃO}

Buscar a Sustentabilidade em transporte, a dinâmica das cidades frente às modernas necessidades de mobilidade urbana é uma realidade que chegou a Mato Grosso.

Em 2008 Magalhães desenvolveu um Modelo de Demanda de Transportes Integrados com Intermodalidade no
Aglomerado Urbano, Cuiabá - Várzea Grande, utilizando o Planejamento de Transportes o clássico Modelo de Previsão de Demanda, "Modelo de Distribuição de Viagens" para determinar as frações das viagens resultantes da integração de modais (ônibus, lotação, táxi, micro-ônibus - escolar). A invasão dos carros de uso particular, pois a média ocupacional de um veículo nas grandes cidades é menor que dois passageiros por automóveis, o que 
aumenta o número de carros transitando e dificulta a circulação. O trabalho visou colaborar coma minimização do problema redistribuindo o fluxo dos modais no aglomerado urbano Cuiabá - Várzea Grande, onde já se observava problemas de circulação, de modo a fornecer aos usuários de transporte mais de uma alternativa aos seus deslocamentos e a conseqüente redução no número de veículos circulando. Os resultados obtidos foram de importância nos investimentos em infra-estrutura e no planejamento do sistema de transportes, ou incentivo ao uso do transporte público.

Com as obras na região metropolitana de Cuiabá, as principais vias de acesso foram desviadas para o interior dos bairros, inicialmente era para serem concluídas as obras de infra-estrutura antes do inicio da Copa do Mundo e mesmo tendo passado mais de um ano após o fim da Copa no Brasil, os cidadãos cuiabanos ficaram com uma herança de obras

\section{REVISÃO DE LITERATURA}

Uma das principais e mais caras obras em Cuiabá era a implantação do Veículo Leve Sobre Trilho-(VLT)Cuiabá, onde esse representaria importante modal que atenderia a região Metropolitana de Cuiabá-MT, o modelo foi apresentado pelo Governo do Estado como alternativa para melhorar a mobilidade inacabadas, deixando o trânsito na capital Mato-grossense caótico em varias regiões.

Os cursos voltados a Segurança do Trabalho, qualificam o cidadão para auxiliar a criar ambientes saudáveis e contribuir com a melhoria da qualidade de vida. Conhecer melhor a área de Segurança do Trabalho e saber como construir uma carreira de sucesso melhorando a vida das pessoas.

O profissional da área de segurança que for atuar na área de transportes precisa conviver com a rotina da empresa de transporte, conhecer as técnicas necessárias para garantir que o condutor ofereça um transporte adequado aos passageiros, evitando ou prevenindo acidentes.

Neste trabalho será abordada a problemática causada pelas obras inacabadas, que deveriam ser finalizadas para atender transporte durante o evento da copa. Bem como as questões relacionadas à segurança do trabalhador na área de transporte.

urbana na Região Metropolitana, durante e após a Copa do Mundo FIFA de 2014.

Na Figura 1 são mostradas as regiões onde houve obras de desbloqueio e desvio de tráfego.

Figura 1: Obras de desbloqueio e desvio de tráfego

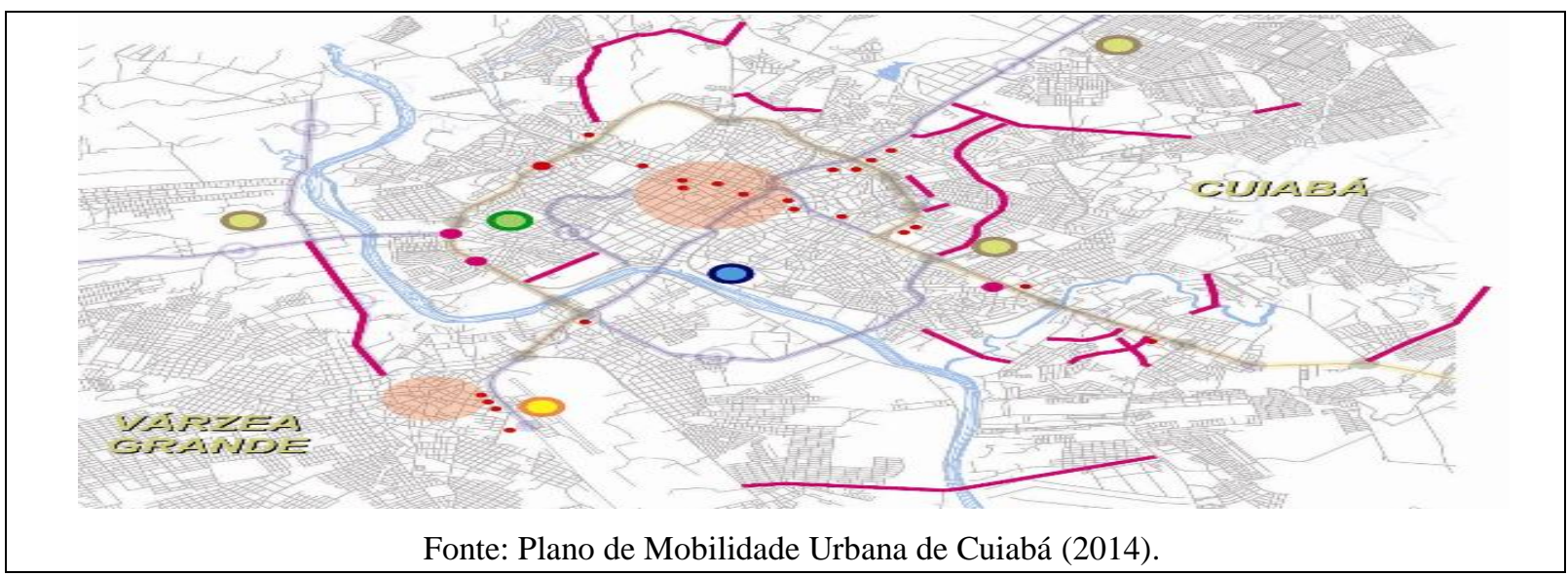


O sistema VLT foi projetado para atender $22,2 \mathrm{~km}$ de extensão dividido em duas linhas, a primeira linha será implantada ligando o Centro Político Administrativo (CPA), em Cuiabá ao Aeroporto Internacional Marechal Rondon, em Várzea Grande, a segunda linha ligará a Região do Coxipó ao Centro Sul, ambas em Cuiabá. O sistema terá 32 estações e tem o custo estimado em 1,4 bilhões de reais (Governo do Estado 2013).

O VLT cuiabano prevê um sistema com 40 composições de 44 metros cada. Cada uma destas composições comporta até 71 passageiros sentados. Com uma composição em tráfego por estação no intervalo de 3 minutos, nos horários de pico, haverá uma demanda de até $8 \mathrm{mil}$ passageiros. A tarifa prevista, segundo o governo, era de $\mathrm{R} \$ 1,75$ a custo atualizado em setembro de 2012. Cada uma das estações deveria receber um módulo de integração com o transporte coletivo tradicional (ônibus).

Conforme a equipe técnica da Secopa, o VLT conviverá com o trânsito em uma via prioritária, mas deverá respeitar a sinalização. O novo sistema prevê a instalação de sinalizadores para sincronia com o tráfego normal de veículos. Assim, o VLT terá a prioridade de tempo nos semáforos. Um sistema matemático calculará o tempo para as composições alternarem velocidade e executarem cruzamento de vias sem a necessidade de parada. Na Tabela 1 será apresentado o sistema proposto.

Tabela 1- Sistema para atender a região Metropolitana

\begin{tabular}{ccccc}
\hline Linha & Terminais & Extensão $(\mathbf{k m})$ & Estações & Funcionamento \\
\hline 1 & Aeroporto $\leftrightarrow$ CPA & 15 & 22 & Em Obras \\
2 & Centro $\leftrightarrow$ Coxipó & 7,2 & 11 & Em Obras \\
\hline
\end{tabular}

Várzea Grande é a segunda cidade mais populosa do estado, está separada de Cuiabá, pelo Rio Cuiabá. Pertence à Região Metropolitana do Vale do Rio Cuiabá.

O Aeroporto de Cuiabá e Várzea Grande - Marechal Rondon, também conhecido por Aeroporto Internacional Marechal Rondon é o principal aeroporto do Estado e o segundo mais movimentado aeroporto da região Centro Oeste.

O transporte coletivo de Várzea Grande está monopolizado pela empresa União Transportes que opera o sistema de ônibus urbano municipal em 2 linhas estruturais, que fazem a ligação dos bairros com o centro da cidade e ao centro de Cuiabá através do Terminal de Integração André Maggi.

Segundo o DETRAN-MT, a frota de Várzea Grande e Cuiabá são compostas por um total de 519.771 veículos (143.439 e 376.332 respectivamente), sendo que 254.374 são automóveis (63.445 e 190.929 respectivamente) e 149.817 são motocicletas/motonetas (50.648 e 99.169 respectivamente) (est. DENATRAN, julho de 2015).

Os principais pontos geradores tráfego em Cuiabá são destacados na Figura 2 e os corredores viários na Figura 3. 
Figura 2: Principais pontos geradores de tráfego da região metropolitana de Cuiabá

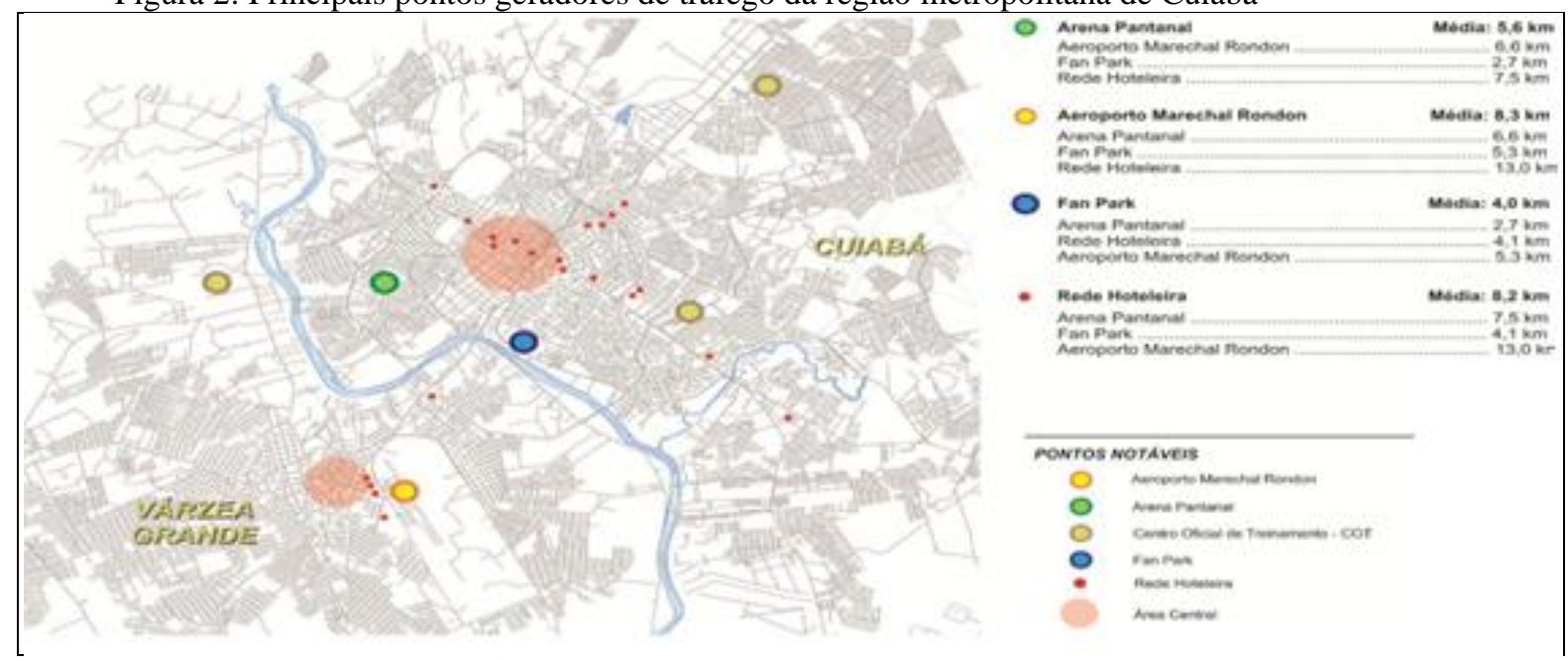

Fonte: Plano de Mobilidade Urbana de Cuiabá (2014).

Figura 3: Principais corredores viários da região metropolitana de Cuiabá

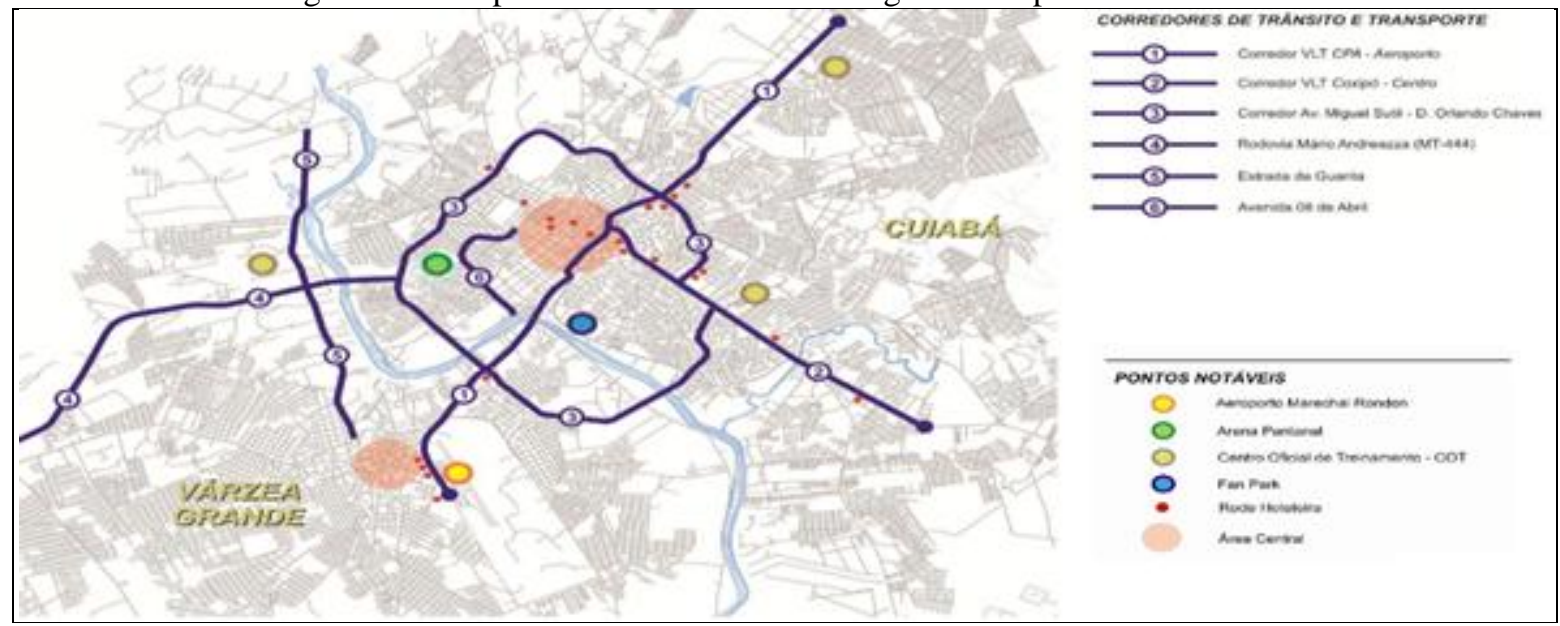

Fonte: Plano de Mobilidade Urbana de Cuiabá, (2014).

Após a paralisação das obras por parte do Ministério Público, por suspeitas de irregularidades nos processos, a população ficou a mercê de obras inacabadas, piorando em muitas regiões a mobilidade urbana, já que em inúmeras obras houve interdição de partes consideradas vitais para a cidade, como por exemplo, a região da Prainha, no centro de Cuiabá, onde se foi interditado uma faixa de rolamento em cada sentido, trazendo a população o desconforto de horas a mais no transito da capital. (Oliveira e Magalhães, 2015).
Conselho Municipal De Transportes (CMT)

O Conselho Municipal de Transportes é um organismo de caráter consultivo ou deliberativo, de representação do poder público e da sociedade civil na gestão da política municipal transporte. Sua regulação em Cuiabá é realizada pela Lei $\mathrm{N}^{\circ} 3214$ de 15 de dez. de 1993 foi alterada pela Lei $\mathrm{N}^{\circ}$ 3.683/97 de 01/12/97 Publicada na GM N ${ }^{\circ}$ 371 de 03/12/97 e Pela Lei $N^{\circ} 4.342 / 02$ de 30/12/02 Publicada na GM N ${ }^{\circ} 632$ de $30 / 05 / 03$. 
As competências do CMT, constam no Art. $5^{\circ}$ da referida lei:

I - Propor e opinar sobre a política municipal de transportes, observadas as demais políticas setoriais e o planejamento urbano;

II - Apreciar e opinar sobre a implantação de plenos e programas relacionados com o sistema de transportes públicos de passageiros, no âmbito da STU;

III - Propor à STU desenvolvimento de estudos e projetos voltados à melhoria do sistema de transportes urbanos;

IV - Apreciar as concepções normativas e decisões operacionais sobre o sistema de transportes públicos urbanos, quando submetidos à sua consideração pela STU; $\mathrm{V}$ - Examinar normas e formas de articulações dos diversos modos de transporte de passageiros visando sua integração física, operacional e tarifária; VI - Promover a integração entre os órgãos atuantes sobre o sistema de transportes públicos urbanos; VII - Apreciar e opinar sobre problemas decorrentes de conflitos de competência que possam vir a existir entre as diversas entidades responsáveis pelo planejamento, implantação e operação do sistema de transportes públicos urbanos;

VIII - Recomendar e opinar quanto a adoção de procedimentos capazes de fortalecer o gerenciamento do sistema de transportes públicos urbanos, inclusive convênios voltados a delegação de competências;

IX - Apreciar e opinar sobre proposta da estrutura tarifária ou outros estudos relacionados com a fixação de tarifas para o sistema de transportes públicos urbanos; $\mathrm{X}$ - Apreciar e encaminhar ao chefe do poder executivo municipal as propostas de reajustes das tarifas vigentes;

XI - Apreciar e propor estudos e medidas relacionadas com o sistema viário de trânsito, que possam contribuir para a melhoria do sistema de transportes públicos urbanos;

XII - apreciar e julgar, em segunda instância os recursos interpostos contra as decisões de superintendência de transportes urbanos, pela aplicação de penalidades por infração às normas que regem o sistema de transportes públicos urbanos;

XIII - Opinar sobre quaisquer assuntos que lhes forem submetidos à apreciação e que digam respeito as suas finalidades, tais como:
A) medidas que visam coordenar, no município, as atividades dos permissionários ou concessionários de transportes coletivos; B) a qualidade dos serviços prestados pelos transportadores;

C) os editais de licitação para exploração de transportes coletivos urbanos; D) quaisquer outros assuntos relacionados com o transporte coletivo urbano, que lhes forem submetidos pelo prefeito municipal; câmara dos Vereadores ou pela STU;

XIV - resolver os casos omissos nesta lei e nos regulamentos do sistema de transportes urbanos, mediante deliberação e votação pela maioria absoluta de seus membros.

Art. $6^{\circ}$ Compete à Prefeitura Municipal, no exercício de suas atividades de gerenciamento do Serviço Essencial de Transporte Coletivo, a prestação dos seguintes serviços: I - atendimento à população nos assuntos relacionados ao serviço de transporte; II - planejamento do Sistema de Transporte Coletivo e a especificação do serviço a ser prestado pelas operadoras; III - medição e fiscalização do serviço concedido; IV - estudos de implantação de terminais de transferências e/ou integração, equipamentos de informação aos usuários, abrigos de ônibus e sinalização de pontos de parada; V implantação de abrigos e de pontos de parada. (Leis do transporte do município de Cuiabá, 2006).

\section{Disponibilidades Relativas à Segurança do Trabalho nos Transportes}

Também serão abordadas nesse artigo as normas e leis referentes à segurança do trabalho nos transportes, entre eles o transporte público coletivo

Art. 4. Constitui Serviço de Transporte Coletivo, os transportes executados por ônibus, microônibus ou outro meio em uso ou que vier a ser utilizado no futuro, à disposição permanente do cidadão, contra a única exigência de pagamento da tarifa de utilização efetiva, fixada pelo Prefeito Municipal. Parágrafo único. Enquanto essencial, o transporte coletivo deverá ser prestado observando-se as condições de regularidade, continuidade, efíciência, segurança, atualidade, generalidade, cortesia e modicidade das tarifas. (Leis do transporte do município de Cuiabá, 2006). 
Em 2001, 3 (três) Agentes da Inspeção do Trabalho da Delegacia Regional do Trabalho no Estado da Bahia inspecionaram e notificaram todas as 22 (vinte e duas) empresas integrantes do sistema municipal de transporte coletivo de passageiros de Salvador, Bahia. Caso seja feito essa pesquisa atualmente em Cuiabá, acredita-se que todas as empresas de transporte de passageiros também deverão apresentar irregularidades. Em síntese, durante as inspeções foi verificado o cumprimento das cláusulas da convenção acima referida e das disposições previstos na legislação brasileira de segurança e saúde no trabalho, as Normas Regulamentadoras (NRs) da Portaria 3214/78 (3), tais como:

- Organização, composição e funcionamento da Comissão Interna de Prevenção de Acidentes - CIPA

- Dimensionamento e funcionamento do Serviço Especializado em Engenharia de Segurança e em Medicina do Trabalho

- Elaboração e divulgação do Mapa de Riscos

- Elaboração e implementação do Programa de Prevenção de Riscos Ambientais (PPRA) e do Programa de Controle Médico de Saúde Ocupacional (PCMSO)

- Condições de segurança do pátio das garagens (piso, sinalização e iluminação)

- Condições sanitárias e de conforto nos locais de trabalho (instalações sanitárias, vestiários e refeitórios)

- Higienização e limpeza dos locais de trabalho

- Fornecimento e efetiva utilização dos Equipamentos de Proteção Individual EPIs

- Medidas de proteção para prevenção de quedas nas atividades no teto dos veículos

- Medidas de proteção nas tarefas realizadas nas valetas de serviços, com o veículo elevado ou com o veículo com os pneus apoiados no chão

- Medidas de higiene e proteção nas áreas de lavagem de peças

- Medidas de proteção nos serviços de borracharia, chaparia e pintura

- Condições de armazenagem e de abastecimento de líquidos combustíveis

A Prefeitura Municipal promoverá, sempre que entender necessário, a realização de auditoria técnico-operacional nas Operadoras:

Art. 37. A auditoria procederá ao estudo, análise e avaliação do desempenho operacional e empresarial da empresa sob todos os aspectos, especialmente os seguintes: II - técnico-operacionais: equipamentos, principalmente veículos, instalações, tráfego, segurança do serviço, programas e procedimentos de manutenção; (Leis do transporte do município de Cuiabá, 2006).

Baseado nesse artigo da Lei do Transporte do Município de Cuiabá, notase a importância dos aspectos de segurança, não somente para os usuários do transporte publico, mas também para os funcionários do transporte, já que instalações e a segurança do serviço são levados em conta.

\begin{abstract}
Art. 17. São responsabilidades da Operadora, além de outros previstos em lei, neste Regulamento e no vínculo jurídico de delegação do serviço: VI - apresentar, sempre que for exigido, os seus ônibus para vistoria técnica comprometendo-se a sanar, em prazo determinado pela Prefeitura Municipal, as irregularidades que possam comprometer o conforto, a segurança e a regularidade do transporte de passageiros. (Leis do transporte do município de Cuiabá, 2006).
\end{abstract}

Observa-se que de acordo com o artigo $17^{\circ}$, parágrafo $6^{\circ}$ dessa referida lei, todas as operadoras do transporte público devem apresentar seus ônibus para vistorias técnicas, e em casos de irregularidades como os do exemplo citado no estado da Bahia devem ser sanados em 
um prazo, estipulado pela Prefeitura Municipal, de até trinta dias.

Art. 38. Verificada a existência de deficiência administrativa, econômicofinanceira ou técnico-operacional, a Prefeitura Municipal determinará à empresa adoção de medidas saneadoras, visando a corrigir a causa do problema.

Como forma de se enquadrar nas disposições da legislação estabelecida, todas as operadoras devem possuir profissionais capacitados e certificados, para gerirem o processo, com o objetivo de garantir a integridade e segurança de seus funcionários e conseqüentemente de seus usuários.

\section{Empresas de Transporte}

A missão da empresa de transportes de pessoas é atender as necessidades de deslocamento coletivo de pessoas, ou logística em deslocamento de pessoas com segurança e rapidez.

A Política da Qualidade visa "Prestar serviço de transporte coletivo de passageiros de forma que atenda e satisfaça as necessidades dos usuários, cumprindo as normas da URBS e mantendo nossos colaboradores treinados e capacitados para a melhoria continua".

As características das garagens de empresas de transporte coletivo são a diversidade de atividades e de tarefas desenvolvidas num mesmo local de trabalho, objetivando a guarda e a manutenção dos veículos utilizados na operação de um sistema municipal de transporte coletivo. Essas atividades envolvem, além de serviços administrativos, os serviços de armazenagem e abastecimento de combustíveis, limpeza, lavagem e higienização de veículos e de peças, manutenção mecânica e elétrica, serviços de solda, chaparia e pintura, recauchutagem de pneus, serviços de borracharia, movimentação, controle e guarda de veículos, entre outros. Em seus locais de trabalho, em função dessa diversidade de tarefas e atividades, é possível identificar a ocorrência dos mais variados riscos ambientais, sejam eles químicos, físicos ou biológicos. Além destes, são evidentes ainda as ocorrências de riscos denominados ergonômicos assim como as situações de riscos de acidentes de trabalho propriamente ditos.

De acordo com Cardoso, (2008), que analisou o Transporte Coletivo Urbano de São Paulo sob a Ótica dos Riscos e Carências Sociais. A desigualdade social resulta de diversos fatores como: $\mathrm{O}$ desempenho da economia, as condições socioeconômicas das diferentes populações que habitam as cidades, a distribuição urbana, principalmente o fosso espacial entre os locais de moradia, as atividades e a infra-estrutura como hospitais, escolas, etc. e o atendimento de transporte a população nas diferentes regiões da cidade, principalmente o transporte coletivo público.

A qualidade do atendimento do transporte coletivo urbano as diferentes populações dependem: Do número de linhas disponíveis, da frequiência e destinos das linhas, das necessidades de deslocamento das populações, do custo do transporte reativo aos ganhos da população.

\section{Atividades Realizadas Por Técnico em Segurança em Empresa de Transportes}

As atividades em empresas de transportes compreendem 6 etapas devidamente realizadas:

1- Treinamentos

2- Realização de ginástica laboral com os funcionários

3- Vistoria nos postos de trabalho

4- Levantamento de problemas diversos, como sinalização de segurança

5- Prazos de validade dos extintores

6- Situação da iluminação 


\section{Transportes Coletivo de Passageiros - Modal Rodoviário:}

O Decreto 5296/2004, em seus artigos 38 e 39, dispõem que:

"Caberá às instituições e entidades que compõem o Sistema Nacional de Metrologia, Normalização e Qualidade Industrial - Sinmetro desenvolver programas de avaliação da conformidade e elaborar normas técnicas para:

- a fabricação de veículos e de equipamentos de transporte coletivo rodoviário,

- a adaptação dos veículos que já se encontram em circulação.

Analisando a ocorrência de acidentes de trabalho segundo o ramo de atividade, constata-se que $6.115(1,78 \%)$ dos acidentes registrados no Brasil no ano de 2000 ocorreram entre trabalhadores do setor de transporte rodoviário de passageiros, sendo que $386(2,01 \%)$ destes eventos foram classificados como doença do trabalho.

De acordo com o DNIT foi também realizada uma audiência pública, em 17/10/2008, em Xerém/RJ, com o objetivo de debater itens polêmicos da norma técnica ABNT/NBR 15570:2008 Especificações técnicas para fabricação de veículos com características urbanas para transporte coletivo de passageiros. Em decorrência dessa audiência, foi estendido o prazo para atendimento de itens da norma, atendendo ao pleito dos fabricantes. Disponível em http://www.inmetro.gov.br/qualidade/acess ibilidade/transporte-rodoviario.asp (2013).

Tempo de Condução no Setor dos Transportes Rodoviários Urbanos

O Regulamento estabelece disposições novas e mais simples relativas aos tempos de condução e aos períodos de repouso para condutores de ônibus urbano, que é de intervalo mínimo de 30 minutos para cada 4 horas trabalhadas, (segundo a lei $\mathrm{n}^{\circ} 12$. 619, de 30 de abril de 2012). Define as responsabilidades das empresas de transportes e dos condutores, bem como as possíveis exceções. Contém disposições relativas ao controle e avaliação do Regulamento e relativas a sanções em caso de infração.

"As ordens da diretoria das empresas são para cumprir a norma, os funcionários que trabalham diretamente com o transporte, como no caso dos motoristas, devem trabalhar por período de 8 horas, para evitar acidentes, obedecer ao intervalo de 30 minutos".

Serviços Especializados em Engenharia de Segurança e em Medicina do Trabalho (SESMT)

A empresa de Transportes precisa observar as regras da NR-4 da Portaria $n^{\circ}$ $3214 / 78$,

As empresas de transporte rodoviário de passageiros, regular, urbano, CNAE: 60.23.2, estão classificadas como grau de risco 3 (três) e estão obrigadas a constituir o SESMT a partir de um número total de 101 (cento e um) empregados no estabelecimento.

Comissão Interna de Prevenção de Acidentes (CIPA)

De acordo com os quadros da CIPA NR-5 da Portaria $n^{\circ}$ 3214/78,

As empresas de transporte rodoviário de passageiros, regular, urbano, CNAE: 60.23.2, estão classificadas no Grupo "C-24 - Transporte" e estão obrigadas a constituir a CIPA a partir de um número total de 20 (vinte) empregados no estabelecimento.

\section{Mapa de Riscos}

A elaboração obrigatória do Mapa de Riscos é estabelecida pela NR-5, item 5.16. "a", da Portaria no 3214/78

Tem por objetivo reunir as informações necessárias para estabelecer o diagnóstico da situação de segurança e saúde no trabalho na empresa. Elaborar o Mapa de Riscos é atribuição dos integrantes da Comissão 
Interna de Prevenção de Acidentes (CIPA), com a participação do maior número de trabalhadores. Na elaboração do mapa, busca-se conhecer o processo de trabalho, identificar os riscos existentes no local analisado e, ao mesmo tempo, possibilitar a troca e divulgação de informações entre os trabalhadores, bem como estimular sua participação nas atividades de prevenção. $\mathrm{O}$ conhecimento e a percepção que os trabalhadores têm do processo de trabalho e dos riscos ambientais presentes, incluindo os dados consignados no Mapa de Riscos, devem ser considerados para fins de planejamento e execução do PPRA.

\section{Programa de Controle Médico de Saúde Ocupacional (PCMSO) Programa de Prevenção de Riscos Ambientais (PPRA)}

O PCMSO, cuja obrigatoriedade foi estabelecida pela NR-7 da Portaria 3214/78,

É um programa médico que deve ter caráter de prevenção, rastreamento e diagnóstico precoce dos agravos à saúde relacionados ao trabalho. Todas as empresas, independente do número de empregados ou do grau de risco de sua atividade, estão obrigadas a elaborar e implementar o PCMSO, que deve ser planejado e implantado com base nos riscos à saúde dos trabalhadores, especialmente os riscos identificados nas avaliações previstas no Programa de Prevenção de Riscos Ambientais (PPRA). A norma estabelece, ainda, que o programa deverá obedecer a um planejamento em que estejam previstas as ações de saúde a serem executadas durante $\mathrm{o}$ ano, devendo estas ser objeto de relatório anual. $\mathrm{O}$ relatório anual deverá discriminar, por setores da empresa, o número e a natureza dos exames médicos, incluindo avaliações clínicas e exames complementares, estatísticas de resultados considerados anormais, assim como o planejamento para o ano seguinte.

\section{Programa de Prevenção de Riscos Ambientais (PPRA)}

De acordo com a NR-9 da Portaria 3214/78,

Todas as empresas, independente do número de empregados ou do grau de risco de suas atividades, estão obrigadas a elaborar e implementar o PPRA, que tem como objetivo a prevenção e o controle da exposição ocupacional aos riscos ambientais, isto é, a prevenção e o controle dos riscos químicos, físicos e biológicos presentes nos locais de trabalho. Um aspecto fundamental é a obrigatoriedade de o empregador reconhecer os riscos ambientais presentes nos diversos locais de trabalho da empresa e assumir prazos para solucionar as questões relativas a esses riscos. Como o programa é permanente, cabe ao empregador formalizar um cronograma anual, com estabelecimento das ações a serem executadas e as metas a serem alcançadas neste período. Uma avaliação global do PPRA deve ser efetuada, sempre que necessário e pelo menos uma vez ao ano, para a avaliação do seu desenvolvimento e realização dos ajustes necessários e estabelecimento de novas metas e prioridades.

Para a prevenção dos riscos ambientais, a empresa recolhia os frascos usados de óleo combustível e acondicionava em local seco e adequado para posterior descarte.

A área de limpeza dos veículos deve sempre ser mantida em ordem. No pátio do lava jato obrigatoriamente deve haver canaletas com grades para facilitar o escoamento da água.

\section{Condições de Segurança do Pátio das Garagens}

Tomando como base a convenção coletiva celebrada em 1996 entre o sindicato dos trabalhadores e o sindicato das empresas de transporte coletivo urbano de passageiros de São Paulo (BRASIL. 1999),

O solo do piso dos pátios deve ser compactado em toda a sua extensão e recoberto por camada de cascalho. As garagens devem garantir as condições mínimas de segurança dos pisos dos pátios, evitando a geração de pó ou a formação de barro ou poças d'água. Os pisos devem ter uma boa drenagem superficial para escoar as águas pluviais e não podem apresentar saliências nem depressões que prejudiquem a circulação de pessoas ou de veículos. Os pátios de garagens devem ser dotados de iluminamento geral, com nível de 
aclareamento mínimo de 20 (vinte) Lux. Além disso, as garagens devem garantir a integridade física dos trabalhadores através de delimitação e sinalização, com faixas ou correntes, das áreas utilizadas por pessoas ou por veículos.

\section{Condições Sanitárias e de Conforto nos Locais de Trabalho}

As condições sanitárias e de conforto nos locais de trabalho foram estabelecidas pela NR-24 da Portaria 3214/78.

\begin{abstract}
As empresas devem manter instalações sanitárias, separadas por sexo, sendo que as áreas destinadas aos sanitários devem atender às dimensões mínimas essenciais, considerando-se satisfatória a metragem de $1,00 \mathrm{~m}^{2}$ (um metro quadrado), para cada sanitário, por 20 (vinte) trabalhadores em atividade. As instalações sanitárias devem ser submetidas a processo permanente de higienização. Quanto aos vestiários, existe a obrigatoriedade da empresa de manter local apropriado dotado de armários individuais observados a separação de sexos. A área do vestiário deve ser dimensionada em função de um mínimo de $1,50 \mathrm{~m}^{2}$ (um metro quadrado e cinquenta centímetros) para 1 (um) trabalhador. Já, em relação às condições de conforto para as refeições, a norma estabelece que deve ser assegurado aos trabalhadores condições suficientes em local que atenda aos requisitos de limpeza, arejamento, iluminação e fornecimento de água potável.
\end{abstract}

\section{Apoio de Veículos}

Nas atividades realizadas no veículo com os pneus apoiados no chão devem ser utilizados calços de metal ou madeira, no formato triangular (cunha) garantindo segurança contra deslizamento, de modo a impedir o deslocamento dos pneus. Já, para a realização de qualquer atividade onde haja necessidade de elevação do veículo, devem ser utilizados cavaletes de ferro ou aço ("preguiças"), com base de sustentação em quatro pontos e cantoneiras de encaixe que impeçam o deslizamento do veículo (BRASIL. 1999)
Caso não seguir as instruções corretas poderá ocorrer acidentes. As empresas devem seguir rigorosamente os procedimentos padrões.

\section{Atividades nas Laterais elou no Teto dos Veículos}

Para a prevenção de quedas nas atividades nas laterais e no teto dos veículos, recomenda-se a utilização de bancadas e/ou escadas dotadas de guardacorpo e rodapé. Além disso, nos trabalhos realizados no teto dos veículos deve ser utilizado cinto de segurança tipo paraquedista preso em trilhos ou cabos de aço fixos ao teto do galpão (BRASIL. 1999).

Neste caso os funcionários devem trabalhar sempre com os equipamentos devido, a fim de evitar riscos de queda e possíveis acidentes graves.

\section{Valetas de Serviços, Áreas de Lavagem de Peças e Borracharia}

Para atender as normas regulamentadoras de segurança, todas as garagens devem possuir um número mínimo de 1 (uma) valeta para cada 130 (cento e trinta) veículos em operação. As valetas devem ter dimensões mínimas de 1,10 a 1,40 metros de profundidade e 0,80 a 1,10 metros de largura, paredes laterais revestidas de material impermeável, piso de chapa de metal vazado com drenagem adequada, iluminação artificial nas paredes laterais e acesso através de escadas ou rampas. Além disso, as valetas devem possuir guia para pneus instalados junto às paredes verticais, de modo a se evitar o acidente. Quando não estiverem sendo utilizadas, as valetas devem permanecer isoladas através de correntes, faixas, grades, cones ou outros dispositivos de isolamento e/ou sinalização, de modo a se evitar os acidentes do tipo queda (BRASIL. 1999) 
O setor de lavagem de peças deve possuir pé-direito de no mínimo 2 (dois) metros, iluminação e circulação de ar adequadas, paredes revestidas com material lavável, piso em chapa de metal vazado, mureta ou bancada de cerca de 1 (um) metro revestida de azulejo, tanque para imersão de peças dotado de tampa, sistema de escoamento de águas servidas e compressor em área isolada e protegido do lado de fora da área de lavagem (BRASIL. 1999)

Nos locais de trabalho onde se realizam atividades de borracharia, os pneus devem permanecer dispostos de modo a manter o local em boas condições de arrumação e limpeza, sendo que os compressores de ar devem ser instalados em local isolado e afastado dos trabalhadores. No levantamento de veículos é recomendável a utilização de macacos do tipo "jacaré". É recomendada, ainda, a utilização de desparafusadeira de rodas dotada de dispositivo silenciador assim como de máquinas de desmonte de pneus. Nas atividades de enchimento de pneus é obrigatória a utilização de dispositivo de proteção do tipo "gaiola", de modo a afastar o borracheiro das proximidades da operação de enchimento. O esmeril deve ser dotado de proteção mecânica de 180 graus na parte superior do rebolo. A água utilizada para teste de vazamento de câmara deve ser substituída no mínimo semanalmente. No local deve haver à disposição dos trabalhadores óculos de segurança, protetor auricular e máscara contra pó. As empresas devem orientar os trabalhadores deste setor quanto ao levantamento adequado de peso (BRASIL. 1999).

Os trabalhadores devem usar óculos de segurança, protetor auricular e máscara contra pó, ou seja, cumprir a legislação.

\section{Condições de Armazenagem e de Abastecimento de Líquidos Combustíveis}

Os tanques de combustíveis de superfície devem ser de concreto ou aço, devendo ser instalados em áreas externas, bem ventiladas e longe de fontes de calor. Os tanques devem ser circundados por diques, muros de proteção ou outro meio que impeça o derramamento de combustível em caso de vazamento, devem ser devidamente aterrados e dotados de dispositivos ("suspiros") que liberem pressões internas excessivas. A área onde estão localizados os tanques deve ser bem iluminada e devidamente sinalizada, além de dispor de extintores adequados e em quantidade suficiente (BRASIL. 1999)

\section{Equipamentos de Proteção Individual- EPIS}

De acordo com a NR-6 da Portaria $3214 / 78$,

A empresa é obrigada a fornecer aos empregados, gratuitamente, Equipamento de Proteção Individual (EPI) adequado ao risco, em perfeito estado de conservação e funcionamento. Considera-se EPI, todo dispositivo ou produto, de uso individual utilizado pelo trabalhador, destinado à proteção de riscos suscetíveis de ameaçar a segurança e a saúde no trabalho. No caso das garagens, o empregador deve fornecer aos trabalhadores os EPIs adequados.

Os mecânicos devem usar mascara e luvas de acordo com a necessidade e exigência do trabalho.

\section{MATERIAIS E MÉTODOS}

\section{Área de estudo}

Cuiabá é a capital do estado brasileiro de Mato Grosso (Figuras 4 e 5). $\mathrm{O}$ município está situado às margens do rio de mesmo nome e forma uma conurbação com o município de Várzea Grande. Segundo a contagem realizada em 2007 pelo IBGE, a população de Cuiabá é de 526.831 habitantes, enquanto que a população dos dois municípios ultrapassa os 750 mil habitantes 
A densidade demográfica de Cuiabá é de 164 habitantes por $\mathrm{km}^{2}$ no território do município. Situado a 180 metros de altitude, as coordenadas geográficas do município Latitude: $15^{\circ} 35^{\prime} \quad 56^{\prime \prime}$ Sul Longitude: $56^{\circ} 5^{\prime} 42^{\prime \prime}$ Oeste. O Cuiabá é um município do Parque Nacional da Chapada dos Guimarães

Figura 4: Localização de Cuiabá no Brasil

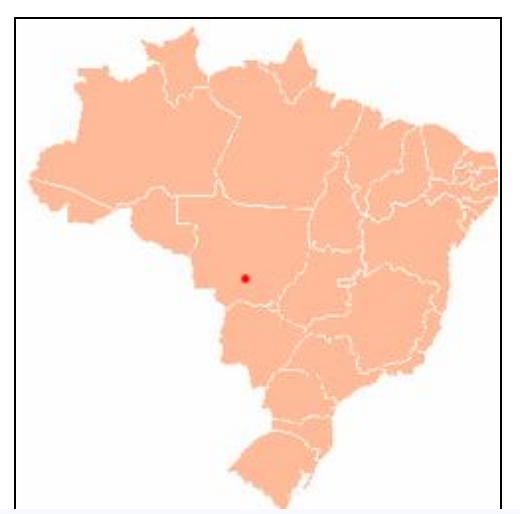

Figura 5: Localização de Cuiabá em Mato Grosso

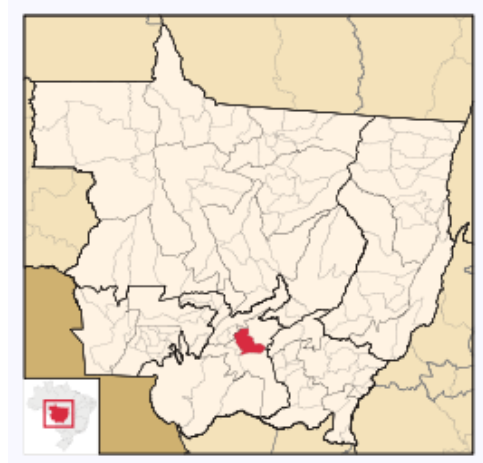

\section{Métodos}

O Trabalho foi desenvolvido baseado em levantamento bibliográfico e visita a garagens de transportadoras locais. Foi levantada a problemática relacionada as questões do transporte público em Cuiabá. Bem como a implantação das obras do VLT.

Foram também observadas as Normas Regulamentadoras-NRs, bem como leis referentes à segurança do trabalho nos transportes, entre eles o transporte público coletivo, relacionadas às atividades laborais dos trabalhadores no setor de transporte e nas oficinas.

\section{CONSIDERAÇÕES}

As garagens de empresas de transporte coletivo urbano caracterizam-se pela diversidade de atividades e de tarefas desenvolvidas num mesmo local de trabalho, objetivando a guarda e a manutenção dos veículos utilizados na operação de um sistema municipal de transporte coletivo. Essas atividades envolvem, além de serviços administrativos, os serviços de armazenagem e abastecimento de combustíveis, limpeza, lavagem e higienização de veículos e de peças, manutenção mecânica e elétrica, serviços de solda, chaparia e pintura, recauchutagem de pneus, serviços de borracharia, movimentação, controle e guarda de veículos, entre outros. Em função dessa diversidade de tarefas e atividades, é possível identificar a ocorrência dos mais variados riscos ambientais, sejam eles químicos, físicos ou biológicos.

Todos os funcionários devem usar equipamentos de segurança adequados a cada função, devidamente inspecionados e em bom estado de conservação.

A formação técnica do profissional em unidades que trabalham com transporte deve ser a base para atuar atentamente em respeito à diversidade de que o campo exige. Além disso, a receptividade da equipe $\mathrm{e} O$ ambiente acolhedor oportunizam a sedimentação de conhecimentos para os iniciantes na equipe.

Outro ponto importante para o bom funcionamento da empresa do ramo de transportes está em relação ao técnico em segurança dos transportes e a experiência em comandar e acompanhar os profissionais da área de transportes para que compreendam a importância fundamental da Segurança do Trabalho integração entre trabalho e experiências profissionais a fim de evitar acidentes e preservar vidas. 
Por se tratar de uma cidade de quase trezentos anos, com um centro histórico travado por ruas de bitóla estreita, sem um plano viário que as modernize, e com muitos prédios antigos tombados pelo patrimônio histórico, o centro de Cuiabá não deveria ser utilizado para acesso de veículos, onde obras importantes como a melhoria dos acessos a pedestres e o alargamento de calçadas são necessários para a otimização do acesso ao centro histórico da cidade, sendo indispensável um Plano Diretor rigoroso.

O Plano de expansão é um instrumento de relevância, nele devem-se constar as instruções de como atender às novas demandas, incorporando os princípios da sustentabilidade como vetores de desenvolvimento, para um futuro sustentável para o cidadão, para as cidades e para os negócios.

A realidade frente à necessidade de um sistema eficaz de mobilidade, com tecnologias limpas e modelo social e economicamente viável e as oportunidades de negócios. O Trem de Alta Velocidade TAV, ou VLT são alternativas de grande desafio para Cuiabá.

A qualidade e acessibilidade ao transporte coletivo são temas tratados nas áreas da Engenharia de Transporte e Urbanismo, bem como nos cursos de engenharia de segurança do trabalho, embora com enfoques diferentes ambos se referem a qualidade dos transportes oferecidos aos usuários.

Estudando-se as irregularidades segundo as Normas Regulamentadoras (NRs), embora nem todas foram discutidas neste trabalho, observou-se que as normas $n^{\circ}$ NR-4, NR- 5 NR- 6, NR-7, NR-8, NR9, NR-12, NR-16, NR-17, NR-20, NR-23, NR-24, NR-26 são aplicadas as empresas de transportes rodoviário de pessoas, envolvendo o quadro de funcionários das empresas que trabalham na rua e nas área internas das garagens. O engenheiro ou técnico em segurança do trabalho precisa estar habilitado a colocá-las em prática e exigir o cumprimento das empresas, para garantir saúde aos trabalhadores internos e segurança a população que depende do transporte público.

Em relação ao custo do transporte em Cuiabá, em 2013 foi estimada uma tarifa para o VLT de R \$1,75 ( Um real e setenta e cinco). Esse valor atualizado até outubro 2015 pelo índice IGP-M seria $\mathrm{R} \$ 2,10$, ( dois reais e dez) fora da realidade local, em que o transporte público custa aproximadamente $\mathrm{R} \$ 3,50$, ( Três reais e cinqüenta)

Assim que as obras do VLT forem concluídas em Cuiabá e Várzea Grande, para minimizar o custo das tarifas, para que se torne um economicamente transporte viável à população, o poder público local deverá estudar uma forma de subsidio. Comparando modais de transporte público adequado, OnibusBRT é 5 a 7 vezes mais barato que metro ou VLT.

\section{REFERENCIAS}

BRASIL Decreto $\mathrm{N}^{\mathrm{o}} 5.296$ de 2 de dezembro de 2004 regulamenta as Leis $\mathrm{n}^{\text {os }}$ 10.048 , de 8 de novembro de 2000 , que dá prioridade de atendimento às pessoas que especifica, e 10.098, de 19 dez 2000, estabelece normas gerais e critérios básicos para a promoção da acessibilidade das pessoas portadoras de deficiência ou com mobilidade reduzida, e dá outras providências. 2004

BRASIL. MPAS - Ministério de Previdência e Assistência Social. Base de Dados Históricos do Anuário Estatístico da Previdência Social - AEPS Infologo. Brasília: MPAS, 2002. (fonte: http://200.244.136.149/infologo/inicio.htm)

BRASIL. MTE - Ministério do Trabalho e Emprego. Departamento de Segurança e Saúde no Trabalho (DSST). Garagens de Empresas de Transporte Coletivo Urbano de São Paulo. Série Convenções Coletivas 
sobre Segurança e Saúde; n.2. Brasília: MTE, DSST, 1999.

BRASIL. MTE - Ministério do Trabalho e Emprego. Secretaria de Segurança e Saúde no Trabalho (SSST). Legislação de Segurança e Saúde no Trabalho. Brasília: MTE, SSST, 1999.

Normas Regulamentadoras (NRs) $n^{\circ}$ NR-4, Serviços especializados em engenharia de segurança e em medicina do trabalho. Portaria GM n. ${ }^{\circ}$ 3.214, de 08 de junho de 1978, última alteração Portaria MTE n. ${ }^{\circ}$ 2.018, de 23 de dezembro de 2014

NR-5 Comissão Interna de Prevenção de Acidentes - CIPA. Portaria GM n. ${ }^{\circ} 3.214$, de 08 de junho de 1978. Última alteração Portaria SIT n. ${ }^{\circ}$ 247, de 12 de julho de 2011

NR-6, Equipamento de Proteção Individual - EPI Publicação D.O.U. Portaria GM n. ${ }^{\circ} 3.214$, de 08 de junho de 1978. Última alteração Portaria SIT n. ${ }^{\circ}$ 292, de 08 de dezembro de 2011

NR-7, Programa de Controle Médico de Saúde Ocupacional. Publicação D.O.U. Portaria GM n. ${ }^{\circ} 3.214$, de 08 de junho de 1978. Última alteração Portaria MTE n. ${ }^{\circ}$ 1.892, de 09 de dezembro de 2013.

NR-8, Edificações. Publicação D.O.U. Portaria GM n. ${ }^{\circ} 3.214$, de 08 de junho de 1978.Última alteração Portaria SIT n. ${ }^{\circ} 222$, de 06 de maio de 2011.

NR-9, - Programa de prevenção de riscos ambientais. Publicação D.O.U. Portaria GM n. ${ }^{\circ}$ 3.214, de 08 de junho de 1978. Alterações/Atualizações Portaria MTE n. ${ }^{\circ} 1.471$, de 24 de setembro de 2014

NR-12, Segurança no trabalho em máquinas e equipamentos Publicação D.O.U. Portaria GM n. ${ }^{\circ}$ 3.214, de $08 \mathrm{de}$ junho de 1978. Última alteração Portaria MTE n. ${ }^{\circ} 857$, de 25 de junho de 2015.

NR- 16, Atividades e operações perigosas. Publicação D.O.U. Portaria GM n. 3.214 , de 08 de junho de 1978. Última alteração Portaria MTE n. ${ }^{\circ}$ 05, de 07 de janeiro de 2015

NR-17, Ergonomia Publicação D.O.U. Portaria GM n. ${ }^{\circ}$ 3.214, de 08 de junho de 1978. Última alteração Portaria SIT n. ${ }^{\circ} 13$, de 21 de junho de 2007

NR-20, Segurança e saúde no trabalho com inflamáveis e combustíveis. Publicação D.O.U. Portaria GM n. ${ }^{\circ}$ 3.214, de 08 de junho de 1978. Última alteração Portaria MTE n. ${ }^{\circ} 1.079$, de 16 de julho de 2014

NR-23, Proteção Contra Incêndios Publicação D.O.U. Portaria GM n. ${ }^{\circ}$ 3.214, de 08 de junho de 1978. Última alteração Portaria n. ${ }^{\circ} 221$ de 06 de maio de 2011

NR-24, Condições Sanitárias e de Conforto nos Locais de Trabalho. Publicação D.O.U. Portaria GM n. ${ }^{\circ} 3.214$, de 08 de junho de 1978 06/07/78 Atualizações/Alterações D.O.U. Portaria SSST n. ${ }^{\circ}$ 13, de 17 de setembro de 1993.

NR-26; Sinalização de Segurança Publicação D.O.U. Portaria MTb n. ${ }^{\circ}$ 3.214, de 08 de junho de 1978. Alterado pela Portaria MTE n. ${ }^{\circ} 704$, de 28 de maio de 2015

Cardoso, C.E. Paiva. Análise do Transporte Coletivo Urbano sob a Ótica dos Riscos e Carências Sociais, São Paulo, 2008, Tese de Doutorado PUC/SP.

Cuiabá-MT Lei Que Regulamenta o Conselho Municipal de Transporte, Câmara Municipal de Cuiabá. LEI No 3214 de 15 de dez. de 1993. AUTOR: Executivo Municipal, Publicada na Gazeta Municipal $\mathrm{N}^{\circ} 178$ DE 15/12/93. Alterada Pela Lei ${ }^{\circ}$ 
3.683/97 de 01/12/97 Publicada $\mathrm{Na} \mathrm{Gm} \mathrm{N}$ 371 de 03/12/97 E Pela Lei No 4.342/02 de $30 / 12 / 02$. Publicada na GM N $\mathrm{N}^{\circ} 632 \mathrm{DE}$ $30 / 05 / 03$. Dispõe sobre a regulamentação do conselho municipal de transporte e dá outras providências

Magalhães, Sérgio Luiz Morais, Planejamento de Transporte de um Aglomerado Urbano com Intermodalidade por meio de um Modelo de Transportes Integrados Tese apresentada à COPPE/UFRJ, agosto / 2008

(Mato Grosso Leis do Transporte do Município Lei $n^{\circ} 4094 / 2001$ e Decreto ${ }^{\circ}$ $4214 / 2004$ - lei do transporte coletivo de Cuiabá, disponível em: www.cuiaba.mt.gov.br/upload/arquivo/LE GISLACAOSMTU_2006.pdf).

Miranda, Carlos Roberto et al Garagens de Empresas de Ônibus: Uma resposta de Ação Preventiva na Área de Segurança e Saúde no Trabalho. Disponível em (www.saudeetrabalho.com.br) 2013

Miranda, C. R.; Dias, C. R.; Amorim M. G. Garagens de Empresas de Ônibus: Uma Proposta de Ação Preventiva na Área de Segurança e Saúde no Trabalho disponível em www.segurancaetrabalho.com.br/ download/garagens-artigo.doc, acessado em Nov/2013
USA. CDC - Center for Disease Control and Prevention. Epidemiology Program Office. Division of Public Health Surveillance and Informatics. Epi Info 2000 Version 1.0.5. Atlanta, Geórgia, USA: 2002 (fonte: www.cdc.gov/epiinfo/ei2000.htm ).

Web sites: Disponível em: http://www.vcsorriso.com.br/institucional/ \#empresas Acessado em (2015)

Disponível em http://www.inmetro.gov.br/qualidade/acess ibilidade/transporte-rodoviario.asp

Acessado em (2015)

Disponível em:

http://www.dnit.gov.br/rodovias/operacoes -rodoviarias/percepcao-de-risco-no-transito Acessado em (2013)

Disponível em: http://www.denatran.gov.br/frota2015.htm Acessado em (setembro 2015)

Disponível em: http://www.mobilize.org.br/midias/pesquis as/plano-de-mobilidade-urbana-decuiaba.pdf Acessado em (setembro 2015). 